\title{
Effects of the Slot Harmonics on the Stator Current in an Induction Motor with Bearing Fault
}

\author{
Xiangjin Song, ${ }^{1,2}$ Jingtao Hu, ${ }^{1}$ Hongyu Zhu, ${ }^{3}$ and Jilong Zhang ${ }^{4}$ \\ ${ }^{1}$ Department of Information Service \& Intelligent Control, Shenyang Institute of Automation, Chinese Academy of Sciences, \\ Shenyang 110016, China \\ ${ }^{2}$ University of Chinese Academy of Sciences, Beijing 100049, China \\ ${ }^{3}$ School of Electronic and Information Engineering, University of Science and Technology Liaoning, Anshan 114044, China \\ ${ }^{4}$ Industrial Control Network and Systems Department, Shenyang Institute of Automation, Chinese Academy of Sciences, \\ Shenyang 110016, China \\ Correspondence should be addressed to Jingtao Hu; hujingtao@sia.cn
}

Received 27 October 2016; Revised 20 February 2017; Accepted 9 March 2017; Published 5 April 2017

Academic Editor: Anna Vila

Copyright (c) 2017 Xiangjin Song et al. This is an open access article distributed under the Creative Commons Attribution License, which permits unrestricted use, distribution, and reproduction in any medium, provided the original work is properly cited.

\begin{abstract}
Bearing faults are the most frequent faults of induction motors. The current spectrum analysis is an easy and popular method for the monitoring and detection of bearing faults. After a presentation of the existing fault models, this paper illustrates an analytical approach to evaluate the effects of the slot harmonics on the stator current in an induction motor with bearing fault. Simple and clear theoretical analysis results in some new current characteristic frequencies. Experimental tests with artificial bearing outer raceway fault are carried out by measuring stator current signals. The experimental results by spectral analysis of the stator current agree well with the theoretical inference.
\end{abstract}

\section{Introduction}

Induction motors (IMs) play a critical role in agricultural, industrial, and commercial sectors. Such popularity is increasing mainly because of their simple organizational structure, easy maintenance, premium power efficiency, and high reliability. Even if induction motors are reliable, unexpected failures may still occur under environmental stresses which could lead to production shutdown and extra maintenance cost. Thus, the online monitoring and fault diagnosis of induction motors have been extensively studied and many techniques have been published about this issue, as described in [1]. The IMs faults can be divided into two major categories: electrical defects (rotor faults, stator winding failures, etc.) and mechanical faults (bearing faults, eccentricities, and shaft misalignment). Among them, bearing-related faults account for over $40 \%$ (large machines) to $90 \%$ (small machines) of total faults [2]. Therefore, it is important to research on rolling-element bearing faults diagnosis.

Depending on the type of the measured variables, methods that are used for diagnosing IM bearing faults can be categorized as acoustic emission, temperature measurements, vibration monitoring, motor current signal analysis (MCSA), and so forth. Among them, vibration signals have been widely applied in IM bearing faults detection [3-6]. However, this method is invasive and needs to install special sensor on the motor. Not only does this increase the investment and maintenance workload, but also the vibration sensors are sensitive to mounting position [7, 8]. Therefore, MCSA has received considerable attention due to its low cost and noninvasive nature in recent years [7, 9-14]. Moreover, stator current signals are often previously measured for control purposes in the drive system and can be analyzed remotely and online $[9,11]$.

The relationship between bearing vibration characteristics and current spectrum effects was first proposed by Schoen et al. based on the generation of a rotating eccentricity, but the author did not give a detailed theoretical derivation [14]. Based on the studies mentioned above, Blödt et al. put forward a new mathematical model by analyzing the combinations of permeance wave and magneto-motive force (MMF) harmonics, taking into consideration the radial rotor 
movement and bearing faulted-related load torque variations [13]. The rotor was assumed to be perfectly centered when there is no contact between a ball and the defect, and the electromagnetic torque was supposed to be stable in Blödt et al. [13]. A theoretical analysis of the physical link between faults which was modeled as a torque disturbance and current components was obtained by accounting that the electromagnetic torque was subjected to minor variations [6]. A rectangular pulse model was proposed by Cheng et al. viewing the effect of bearing banded failures as a rectangular pulse [15]. A new current eigenfrequencies expression was introduced by $\mathrm{Ma}$ et al. considering the IM carried with bearing fault and inherent eccentricity [16]. The aforementioned models, however, neglected rotor and stator slotting effects which modify the valid airgap permeance. These techniques may lead to unreliable IM fault diagnosis.

In view of the advantages of the aforementioned models, together with the effects of rotor and stator slotting, a more comprehensive mathematical model is proposed in this paper based on rotating wave approach where airgap flux density is determined by the product of permeance and magneto-motive force waves. At last, the theoretical analysis is verified by bearing outer raceway fault detection and the experimental results are well in agreement with the theoretical investigation.

The rest of the paper is constructed as follows. Section 2 gives a brief description of the structure and fault types of a rolling-element bearing. The proposed current characteristics analysis theory is described in Section 3. Section 4 reports the experiment setup and the obtained results for testing the effectiveness of the proposed theory on a threephase induction motor with one healthy and one artificially damaged bearing. Finally, some conclusions of this paper are summarized in Section 5.

\section{The Structure and Fault Types of a Rolling-Element Bearing}

The typical geometric structure of a rolling-element bearing is shown in Figure 1. Rolling-element bearings are mainly composed of the outer and inner raceway, the ball elements, and the cage, which ensures the distances between the ball elements uniformly. On ordinary conditions, bearing faults can be separated into two types, that is, single-point (also called localized or cyclic) and generalized-roughness (also called distributed or noncyclic) faults [17]. Localized faults could be imagined as a small hole, a pit, or a missing piece of material and they affect a localized region [13, 17]. When a localized defective bearing runs at a constant speed, a periodic impact between rolling elements and the raceway is produced $[6,13]$. The existence of such impulsive forces gives rise to an increase in the vibration level $[18,19]$. The characteristic frequencies of these vibrations rely on fault location, bearing geometry, and operating speed [20,21]. Not alike localized faults, generalized-roughness faults greatly worsen the entire area of a bearing element because of the absence of lubrication, erosion, or bearing pollution and are
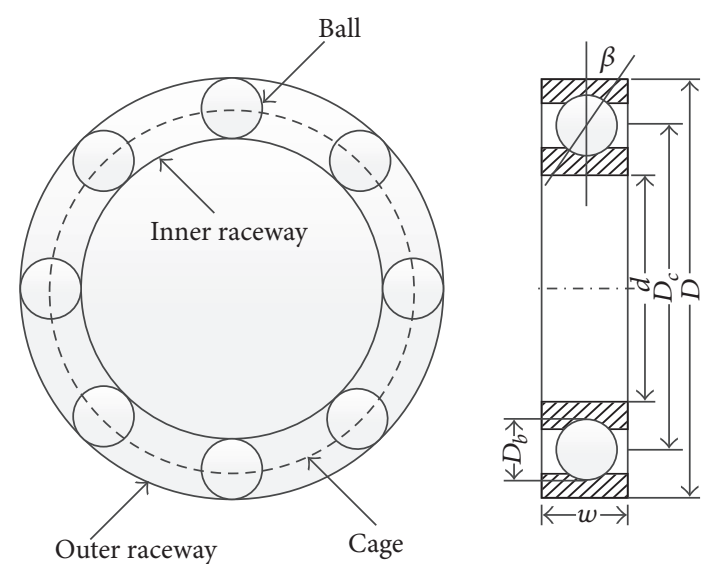

FIGURE 1: Typical structure of a rolling-element bearing with main parameters.

hard to represent by specific frequencies [22, 23]. In this paper, only localized fault is studied.

Localized faults can be usually divided into four categories depending on the affected element, namely, outer raceway fault, inner raceway fault, ball fault, and cage fault. The vibration characteristic frequencies of these faults, when the outer raceway is stationary, are expressed as follows [20]:

$$
\begin{aligned}
& f_{\text {of }}=\frac{N_{b}}{2} f_{r}\left(1-\frac{D_{b}}{D_{c}} \cos \beta\right), \\
& f_{\text {if }}=\frac{N_{b}}{2} f_{r}\left(1+\frac{D_{b}}{D_{c}} \cos \beta\right), \\
& f_{\text {bf }}=\frac{D_{c}}{D_{b}} f_{r}\left(1-\left(\frac{D_{b}}{D_{c}} \cos \beta\right)^{2}\right), \\
& f_{\text {cf }}=\frac{1}{2} f_{r}\left(1-\frac{D_{b}}{D_{c}} \cos \beta\right),
\end{aligned}
$$

where $f_{\text {of }}$ is the outer raceway fault frequency, $f_{\text {if }}$ is the inner raceway fault frequency, $f_{\mathrm{bf}}$ is the ball fault frequency, $f_{\mathrm{cf}}$ is the cage fault frequency, $f_{r}$ is the shaft rotational frequency, $N_{b}$ is the number of balls, $D_{b}$ is the ball diameter, $D_{c}$ is the ball pitch diameter, and $\beta$ is the contact angle between a ball and the raceway.

If the bearings are with a number of rolling elements between 6 and 12, the outer and inner raceway fault frequencies can be computed as follows [12]:

$$
\begin{aligned}
f_{\text {of }} & =0.4 N_{b} f_{r}, \\
f_{\text {if }} & =0.6 N_{b} f_{r} .
\end{aligned}
$$

In rolling-element bearing, the stationary ring (outer raceway in this case) fault happens first due to the stationary ring material in load area receiving more dynamic load cycles than other bearing components (e.g., the rotating ring and rolling elements) [7]. Hence, the outer raceway faults are within the scope of investigations in this paper. 


\section{Current Characteristics Analysis Theory}

In a typical induction motor, the dominant components of stator current are the fundamental supply frequency, the eccentricity harmonics, the slot harmonics, and other components including environmental noise $[24,25]$. The models for bearing fault detection proposed by Blödt et al. are limited that the rotor is perfectly centered when there is no contact between a ball and the defect [13]. The new current eigenfrequencies expression considering the IM carried with bearing fault and inherent eccentricity was introduced by $\mathrm{Ma}$ et al. [16]. However, the other prime components of stator current, namely, the slot harmonics, are ignored. In this section, a more comprehensive mathematical model is proposed, accounting for stator and rotor slot harmonics, airgap eccentricity harmonics, and bearing outer raceway fault harmonics. Some new current characteristic frequencies are discovered around the rotor slot harmonics and can be used for bearing fault detection.

The airgap permeance, accounting for stator and rotor slotting, can be approximated, expressed as follows [26]:

$$
P(\theta, t)=\frac{\delta_{s}(\theta, t) \delta_{r}(\theta, t)}{g(\theta, t)},
$$

where $g(\theta, t)$ is the radial airgap length taking into account bearing fault and inherent eccentricity and

$$
\delta_{s}(\theta, t)=\sum_{n_{s}=0}^{+\infty} \delta_{n_{s}} \cos \left(n_{s} S \theta\right)
$$

is the permeance of airgap with restriction of a slotted stator and a smooth rotor and

$$
\delta_{r}(\theta, t)=\sum_{n_{r}=0}^{+\infty} \delta_{n_{r}} \cos \left(n_{r} R \theta-n_{r} R w_{r} t\right)
$$

is the permeance of airgap with restriction of a slotted rotor and a smooth stator.

$S$ and $R$ are the number of stator and rotor slots, $w_{r}$ is the rotor mechanical rotational speed, $\theta$ is the angular position referring to stator, $\delta_{n_{s}}$ and $\delta_{n_{r}}$ are the amplitudes of permeance related to the stator and rotor slots effects, $n_{s}$ and $n_{r}$ are any integer, and $t$ is the time. Hereafter, $n$ represents any integer.

In the following text, after the explicit mathematical derivation process of the airgap permeance and the airgap flux density, some new characteristic frequencies which can be used for bearing outer raceway fault detection around the rotor slot harmonics are obtained.

Under ideal condition, the airgap length in a machine is constant. However, due to unsuitable assembling and manufacturing process, an inherent level of static and dynamic eccentricity tends to coexist. In the case of static eccentricity, by assuming a smooth stator and rotor surface, the length of the airgap can be expressed as follows [27]:

$$
g_{\text {se }}(\theta)=g_{0}\left(1-\delta_{\text {se }} \cos \theta\right),
$$

where $g_{0}$ is the airgap length in an induction motor under ideal condition and $\delta_{\mathrm{se}}$ is the static eccentricity degree.
In the case of dynamic eccentricity, the length of the airgap can be expressed as follows [27]:

$$
g_{\mathrm{de}}(\theta, t)=g_{0}\left[1-\delta_{\mathrm{de}} \cos \left(\theta-w_{r} t\right)\right],
$$

where $\delta_{\mathrm{de}}$ is the dynamic eccentricity degree.

If Fourier series are developed, then,

$$
\begin{gathered}
\frac{1}{1-\delta_{\mathrm{se}} \cos (\theta)}=\sum_{n_{\mathrm{se}}=0}^{+\infty} \delta_{n_{\mathrm{se}}} \cos \left(n_{\mathrm{se}} \theta\right), \\
\frac{1}{1-\delta_{\mathrm{de}} \cos \left(\theta-w_{r} t\right)}=\sum_{n_{\mathrm{de}}=0}^{+\infty} \delta_{n_{\mathrm{de}}} \cos \left(n_{\mathrm{de}} \theta-n_{\mathrm{de}} w_{r} t\right) .
\end{gathered}
$$

The airgap length of an ideal motor with bearing outer raceway fault can be described as follows [13]:

$$
g_{\text {of }}(\theta, t)=g_{0}\left[1-e \cos (\theta) \sum_{n_{\mathrm{of}}=-\infty}^{+\infty} \delta\left(t-\frac{n_{\mathrm{of}}}{f_{\mathrm{of}}}\right)\right],
$$

where $e$ is the eccentric degree because of the outer raceway fault and $\delta\left(t-n_{\mathrm{of}} / f_{\mathrm{of}}\right)$ is Dirac function.

When the Dirac function is expressed as a complex Fourier series, (9) can be represented as follows:

$$
g_{\text {of }}(\theta, t)=g_{0}\left[1-\sum_{n_{\mathrm{of}}=0}^{+\infty} e c_{n_{\mathrm{of}}} \cos \left(\theta \pm n_{\mathrm{of}} w_{\mathrm{of}} t\right)\right],
$$

where $c_{n_{\text {of }}}=f_{\text {of }} \forall n_{\text {of }}$ and $w_{\text {of }}=2 \pi f_{\text {of }}$.

In order to simplify the airgap permeance coefficient, the fraction $1 /(1-x)=1+x+x^{2}+x^{3}+\cdots \approx 1+x($ for $|x|<1)$ is used. The condition $|x|<1$ is constantly met because the degree of eccentricity confirmed $|e|<1$ to prevent any contact between the rotating rotor and nonrotating stator. Then the airgap permeance with bearing outer raceway fault can be obtained

$$
\begin{aligned}
\delta_{\mathrm{of}}(\theta, t) & =\frac{1}{g_{\mathrm{of}}(\theta, t)} \\
& =\delta_{0}+\sum_{n_{\mathrm{of}}=0}^{+\infty} \delta_{n_{\mathrm{of}}} \cos \left(\theta \pm n_{\mathrm{of}} w_{\mathrm{of}} t\right),
\end{aligned}
$$

where $\delta_{0}=1 / g_{0}$ and $\delta_{n_{\mathrm{of}}}=e \delta_{0} c_{n_{\mathrm{of}}} \forall n_{\mathrm{of}}$.

The airgap length for the induction motor with bearing outer raceway fault and mixed eccentricity can thus be represented as follows [16]:

$$
\begin{aligned}
g(\theta, t)= & g_{0}\left(1-\delta_{\mathrm{se}} \cos \theta\right)\left[1-\delta_{\mathrm{de}} \cos \left(\theta-w_{r} t\right)\right] \\
& \cdot\left[1-\sum_{n_{\mathrm{of}}=0}^{+\infty} e c_{n_{\mathrm{of}}} \cos \left(\theta \pm n_{\mathrm{of}} w_{\mathrm{of}} t\right)\right] .
\end{aligned}
$$

A good approximation for the airgap permeance which takes into account the mixed eccentric motor with bearing outer raceway fault is given by

$$
\begin{gathered}
\delta(\theta, t)=\frac{1}{g(\theta, t)}=\delta_{0} \sum_{n_{\mathrm{se}}=0}^{+\infty} \sum_{n_{\mathrm{de}}=0}^{+\infty} \delta_{n_{\mathrm{se}}, n_{\mathrm{de}}} \\
\cdot \cos \left\{\left(n_{\mathrm{se}} \pm n_{\mathrm{de}}\right) \theta-n_{\mathrm{de}} w_{r} t\right\}
\end{gathered}
$$




$$
\begin{aligned}
& +\sum_{n_{\mathrm{se}}=0}^{+\infty} \sum_{n_{\mathrm{de}}=0}^{+\infty} \sum_{n_{\mathrm{of}}=0}^{+\infty} \delta_{n_{\mathrm{se}}, n_{\mathrm{de}}, n_{\mathrm{of}}} \\
& \cdot \cos \left\{\left(n_{\mathrm{se}} \pm n_{\mathrm{de}} \pm 1\right) \theta-\left(n_{\mathrm{de}} w_{r} \pm n_{\mathrm{of}} w_{\mathrm{of}}\right) t\right\}
\end{aligned}
$$

Then taking into account the interaction of stator and rotor slot harmonics, airgap eccentricity harmonics, and bearing outer raceway fault harmonics, the permeance of the airgap could be written as follows:

$$
\begin{aligned}
P(\theta, t)= & \delta_{s}(\theta, t) \delta_{r}(\theta, t) \delta(\theta, t) \\
= & \delta_{0} \sum_{n_{s}=0}^{+\infty} \sum_{n_{r}=0}^{+\infty} \sum_{n_{\mathrm{se}}=0}^{+\infty} \sum_{n_{\mathrm{de}}=0}^{+\infty} \delta_{n_{s}, n_{r}, n_{\mathrm{se}}, n_{\mathrm{de}}} \cos \left\{\left(n_{s} S \pm n_{r} R \pm n_{\mathrm{se}} \pm n_{\mathrm{de}}\right) \theta-\left(n_{r} R \pm n_{\mathrm{de}}\right) w_{r} t\right\} \\
& +\sum_{n_{s}=0}^{+\infty} \sum_{n_{r}=0}^{+\infty} \sum_{n_{\mathrm{se}}=0}^{+\infty} \sum_{n_{\mathrm{de}}=0}^{+\infty} \sum_{n_{\mathrm{of}}=0}^{+\infty} \delta_{n_{s}, n_{r}, n_{\mathrm{se}}, n_{\mathrm{de}}, n_{\mathrm{of}}} \cos \left\{\left(n_{s} S \pm n_{r} R \pm n_{\mathrm{se}} \pm n_{\mathrm{de}} \pm 1\right) \theta-\left[\left(n_{r} R \pm n_{\mathrm{de}}\right) w_{r} \pm n_{\mathrm{of}} w_{\mathrm{of}}\right] t\right\}
\end{aligned}
$$

Only the stator magneto-motive force (MMF) is taken into account and, neglecting skew, it can be represented by

$$
F_{\text {tot }}(\theta, t)=\sum_{n_{\theta f}=1}^{+\infty} \sum_{n_{w f}=-\infty}^{+\infty} F_{n_{\theta f}, n_{w f}} \cos \left(n_{\theta f} p \theta-n_{w f} w_{1} t\right) \text {, }
$$

where $F$ is the amplitude of stator MMF and $w_{1}$ is the electrical supply frequency.

Then the airgap flux density, deduced from the product of the permeance (14) and MMF (15), can be given by

$$
\begin{aligned}
B(\theta, t)= & \sum_{m_{e}, \Omega_{e}} B_{m_{e}, \Omega_{e}} \cos \left(m_{e} \theta-\Omega_{e} t\right) \\
& +\sum_{m_{f}, \Omega_{f}} B_{m_{f}, \Omega_{f}} \cos \left(m_{f} \theta-\Omega_{f} t\right),
\end{aligned}
$$

where

$$
\begin{aligned}
& m_{e}=n_{s} S \pm n_{r} R \pm n_{\mathrm{se}} \pm n_{\mathrm{de}} \pm n_{\theta f} p \\
& \Omega_{e}=\left(n_{r} R \pm n_{\mathrm{de}}\right) w_{r} \pm n_{w f} w_{1}, \\
& m_{f}=n_{s} S \pm n_{r} R \pm n_{\mathrm{se}} \pm n_{\mathrm{de}} \pm n_{\theta f} p \pm 1 \\
& \Omega_{f}=\left(n_{r} R \pm n_{\mathrm{de}}\right) w_{r} \pm n_{\mathrm{of}} w_{\mathrm{of}} \pm n_{w f} w_{1} .
\end{aligned}
$$

Then, the change in the flux density distribution results in the current having harmonics as follows:

$$
\begin{aligned}
& f_{e}=\left(n_{r} R \pm n_{\mathrm{de}}\right) f_{r} \pm n_{w f} f_{1} \\
& f_{f}=\left(n_{r} R \pm n_{\mathrm{de}}\right) f_{r} \pm n_{\mathrm{of}} f_{\mathrm{of}} \pm n_{w f} f_{1} .
\end{aligned}
$$

The models for bearing fault detection proposed by Blödt et al. show that bearing outer raceway characteristic frequencies $\left|f_{1} \pm n_{\text {of }} f_{\text {of }}\right|$ can be obtained in the stator current spectrum. The current eigenfrequencies expression $\mid f_{1} \pm$ $n_{\text {de }} f_{r} \pm n_{\text {of }} f_{\text {of }} \mid$ was introduced by Ma et al. considering the IM carried with bearing fault and inherent eccentricity. From (19), we can see that the new bearing outer raceway characteristic frequencies $\left|f_{1} \pm n_{\text {of }} f_{\text {of }} \pm\left(n_{r} R \pm n_{\text {de }}\right) f_{r}\right|$ (with $\left.n_{r} \neq 0\right)$ can also arise around the rotor slot harmonics when considering not only the slot harmonics but also mixed eccentricity in an induction motor with bearing fault. These new bearing outer raceway characteristic frequencies have not been found in the aforementioned papers. It should be possible to detect these characteristic frequencies by analyzing the stator current spectrum.

\section{Experimental Results}

To assess the effectiveness of the proposed techniques for IM bearing fault detection, a series of comparisons have been conducted between the spectrum of the stator current in healthy and faulty cases. In a rolling-element bearing, artificially produced defect is introduced by simply drilling a hole in the outer raceway to simulate a localized fault, which is similar to other literatures [9-12].

This section is divided into two parts: first, an overview of the experiment test rig is presented, and then the proposed techniques are verified offline using stator current signals for bearing outer race fault detection.

4.1. Test Rig. Schematic diagram of the experiment setup used in this paper is shown in Figure 2. The rated data of the used induction motor are given in Table 1. The induction motor is mechanically coupled to a DC machine, which feeds an external resistor bank. The motor can be identically loaded at different speed from zero to rated load by adjusting the field voltage of the DC machine. Both machines are fixed on a steel plate test bench resting on a cement floor. A photoelectric speed sensor (SZGB-6) is used to measure the shaft speed. As the used National Instrument Data Acquisition (NI DAQ 6216) card accepts only voltage signal with maximum amplitudes of $\pm 10 \mathrm{~V}$, JLB-21 Hall current sensor is used to gather the current signal first, and then the acquired current signal is converted to proportional voltage signals by conditioning circuit. A PC equipped with DAQ card through a USB cable is used to store them in the memory. A picture of the experimental setup is shown in Figure 3.

The induction machine has two CU6206RZ type bearings (single row and deep groove ball bearings) with a width of 
TABLE 1: Test induction motor rated parameters.

\begin{tabular}{lc}
\hline Nominal power & $3 \mathrm{~kW}$ \\
Nominal rated voltage & $380 \mathrm{~V}$ \\
Nominal rated current & $6.8 \mathrm{~A}$ \\
Frequency & $50 \mathrm{~Hz}$ \\
Pole pairs & 2 \\
Stator slots & 36 \\
Rotor slots & 32 \\
Stator winding connection & $\mathrm{Y}$ \\
\hline
\end{tabular}

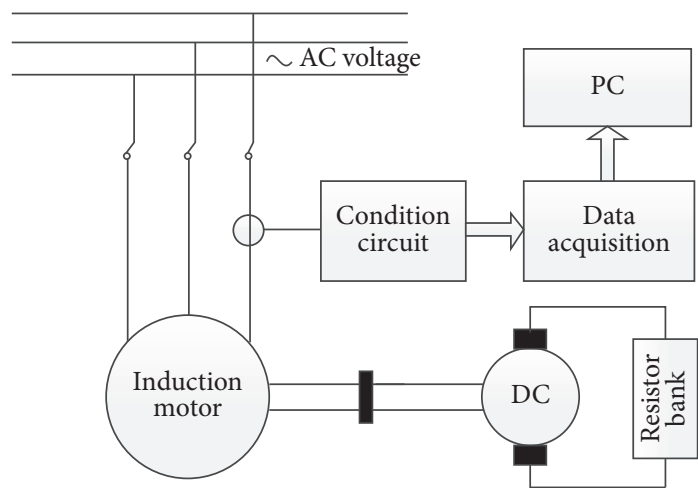

FIgURE 2: Schematic diagram of the experiment setup.

$w=16 \mathrm{~mm}$, an outside diameter of $D=62 \mathrm{~mm}$, an inside diameter of $d=30 \mathrm{~mm}$, and a pitch diameter of $D_{c}=46.0 \mathrm{~mm}$. Each bearing has nine balls $\left(N_{b}=9\right)$ with an approximate diameter of $D_{b}=9.52 \mathrm{~mm}$. The contact angle of the ball with the race $(\beta)$ is assumed to be $0^{\circ}$. Two identical motors are prepared: one motor carries healthy bearings and the other carries one defected bearing which are mounted on the load side of the mechanics. Here, a $6 \mathrm{~mm}$ diameter hole is drilled through the outer race of the bearing to simulate a localized fault. Figure 4 shows the healthy and defected bearings used in the experimental setup.

In the experiments, two induction motors have been considered: a healthy motor and a faulty one affected by bearing outer raceway fault. Firstly, tests have been performed with faulty motor under several different loads by randomly adjusting the field voltage of the DC machine. Then, supplementary test is performed with the healthy motor for the sake of spectra contrastive analysis. All the tests are done in steady-state conditions. The motors under study are fed by a $50 \mathrm{~Hz}$ power supply. The stator current and speed signals are sampled at $50 \mathrm{kHz}$ with a recording length of $25 \mathrm{~s}$.

4.2. Experimental Results. Linear plots of the current spectrum when the motor runs at the shaft speed of $1431 \mathrm{r} / \mathrm{min}$ $(23.85 \mathrm{~Hz})$ are given in Figures 5 and 6 . Figure 5 shows the current spectrum around the fundamental region while Figure 6 depicts the PSHs (principle slot harmonics, PSHs) region. In each figure, the spectrums from a healthy case and a faulty bearing are provided for comparisons. In the frequency range $(0-200 \mathrm{~Hz})$ of the spectrum in the healthy machine (Figure 5(a)), one can see that the frequency components at

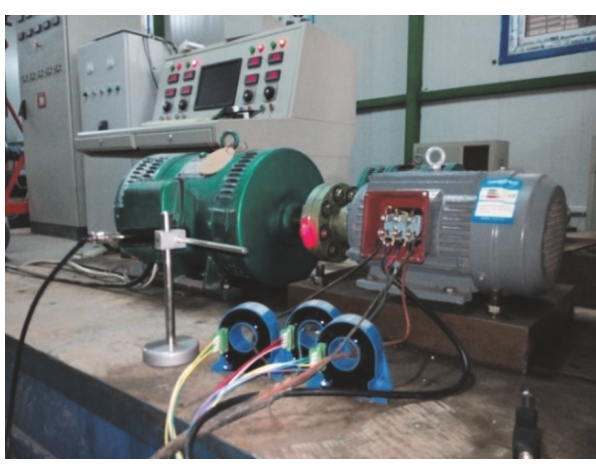

FIGURE 3: Photograph of the experimental setup used for bearing fault detection.

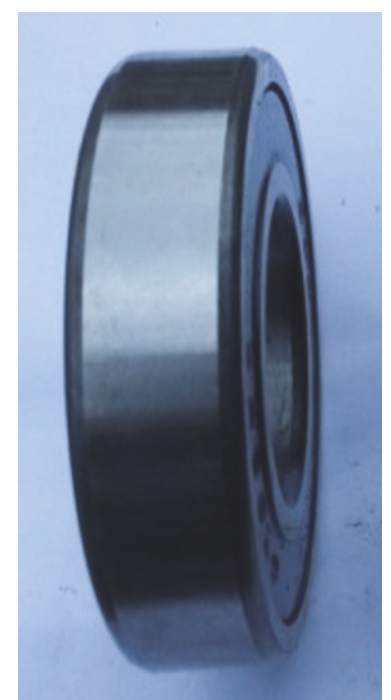

(a)

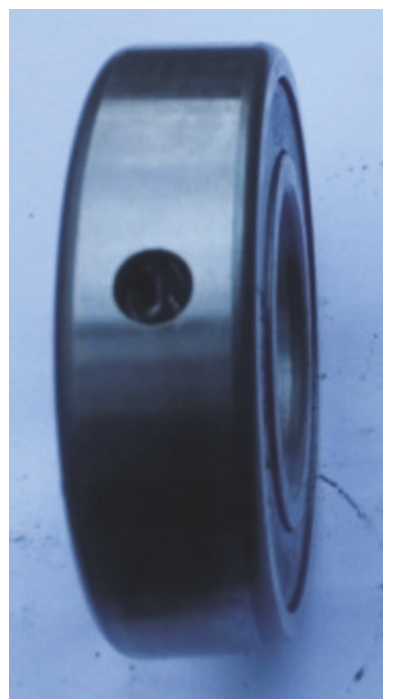

(b)
FIgURE 4: Tested bearings: (a) healthy, (b) outer raceway fault.

$\left|f_{1} \pm f_{r}\right|, f_{1}+2 f_{r}, f_{1}+3 f_{r}$, and $f_{1}+5 f_{r}$ are presented due to the inherent level of eccentricity. Comparisons of Figures 5(a) and $5(\mathrm{~b})$ show that a great number of eccentricity harmonics appeared in Figure 5(b). The magnitudes of eccentricity harmonics are also increased and the frequency component at $3 f_{1}+f_{r}$ can also be observed with the faulty bearing due to the fault-related eccentricity according to (18) and (19) (with $\left.n_{r}=n_{\text {of }}=0\right)$. The fault characteristic frequency at $f_{1}+f_{o}$ is visible and the other fault-related component at $f_{1}+f_{r}+f_{o}$ can also be noticed in the faulty spectrum (Figure 5(b)). These results match with existing studies.

A comparison of the stator current spectrums from a healthy case and a faulty bearing around the PSHs region is shown in Figure 6, considering the effects of the slot harmonics on the current characteristic frequency in an induction motor with inherent eccentricity and bearing fault. The frequency components at $\left|f_{1} \pm R f_{r}\right|$ and $\left|3 f_{1}-R f_{r}\right|$ are already visible in the spectrum of the healthy machine due to the interaction of stator MMF and rotor slot permeance (Figure 6(a)). With an increase in the 3rd slot time harmonic, 


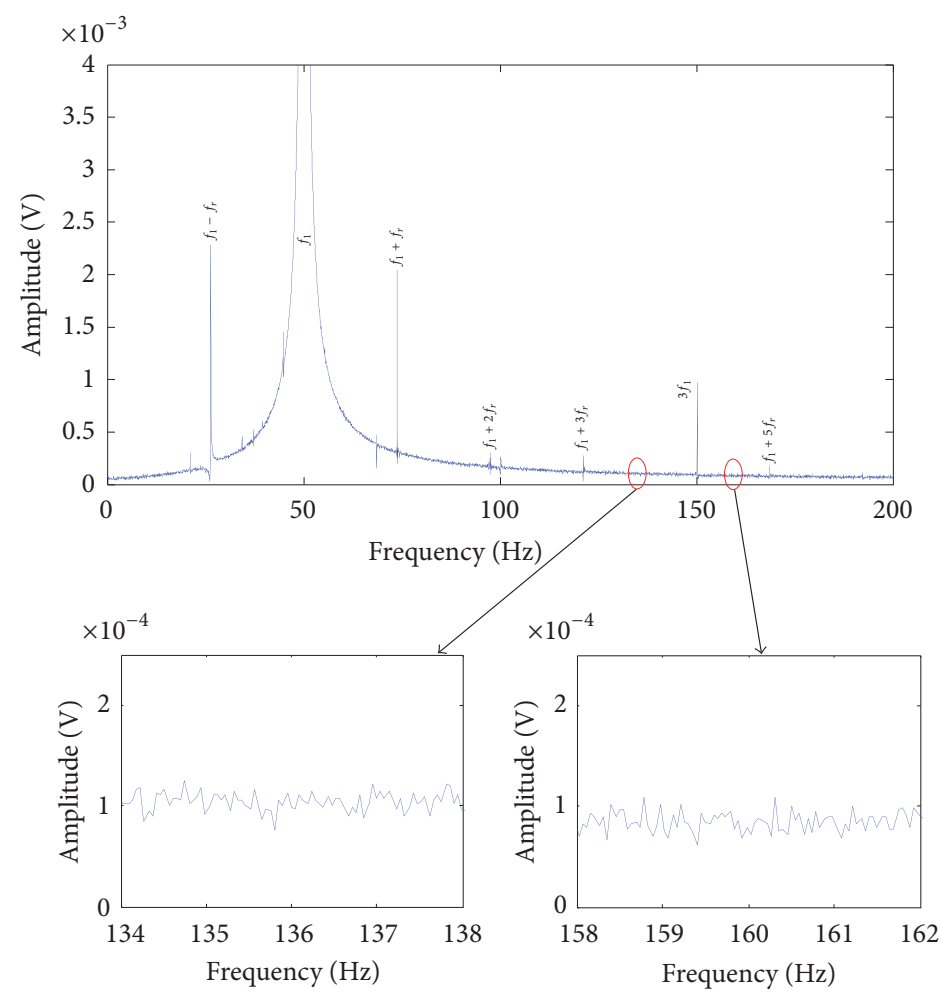

(a)

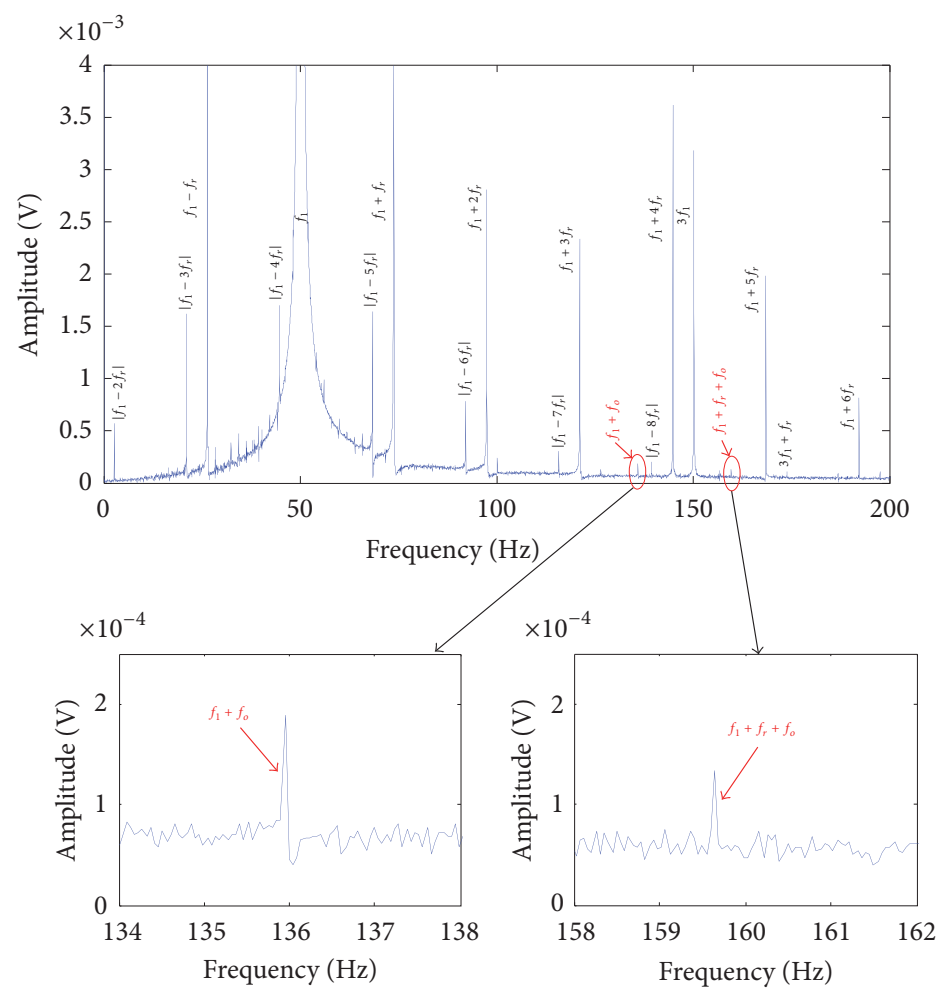

(b)

FIGURE 5: Comparison of stator current spectrums with $50 \mathrm{~Hz}$ supply frequency around fundamental frequency region between healthy IM and IM with outer raceway defect: (a) healthy IM and (b) IM with a bearing outer raceway defect. 


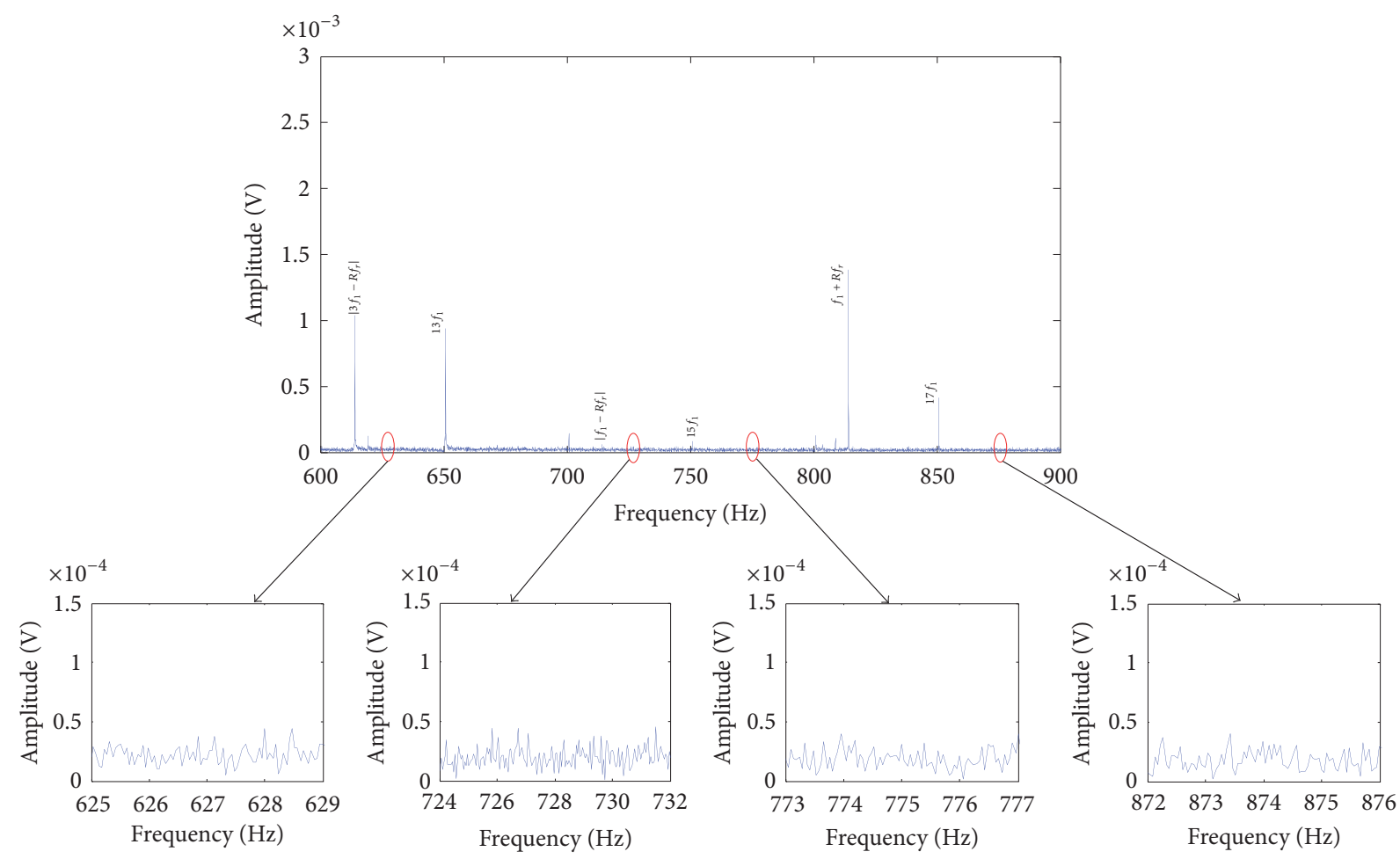

(a)

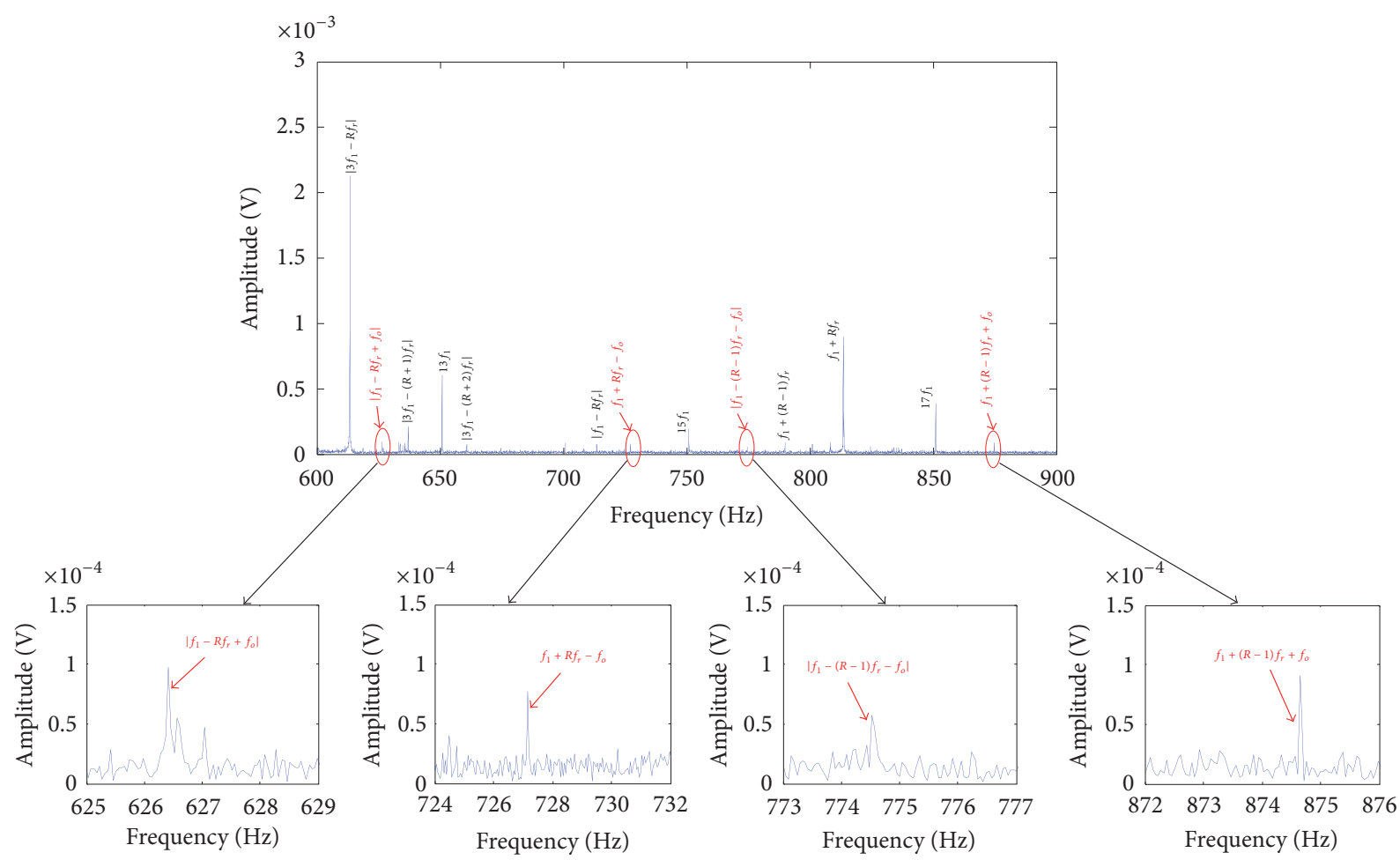

(b)

FIGURE 6: Comparison of stator current spectrums with $50 \mathrm{~Hz}$ supply frequency around PSHs region between healthy IM and IM with outer raceway defect: (a) healthy IM and (b) IM with a bearing outer raceway defect. 


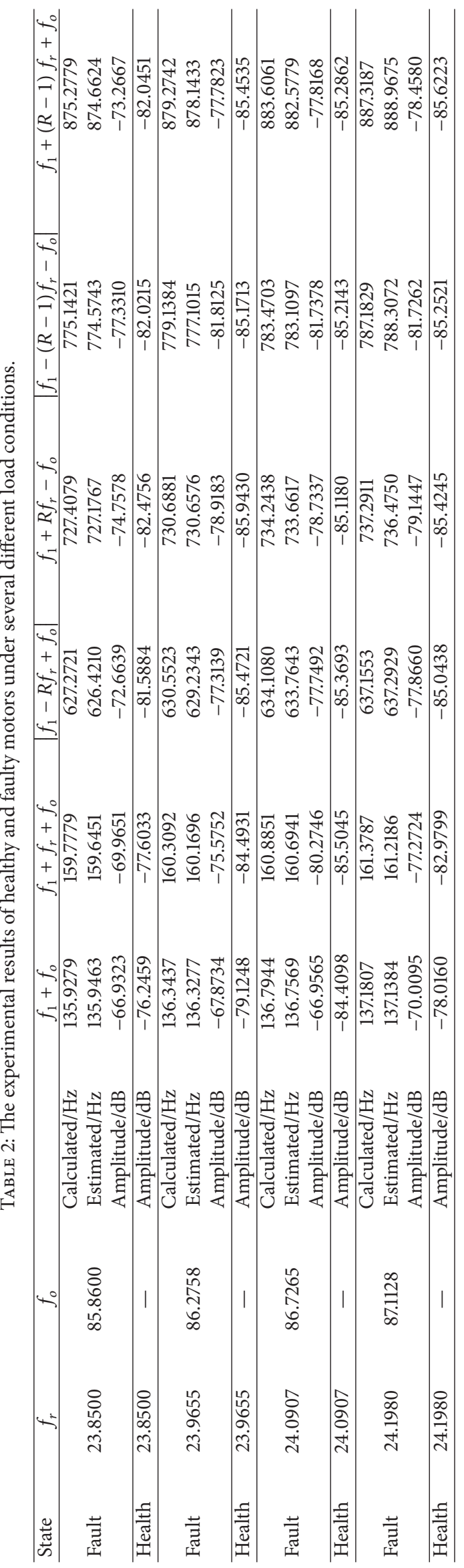




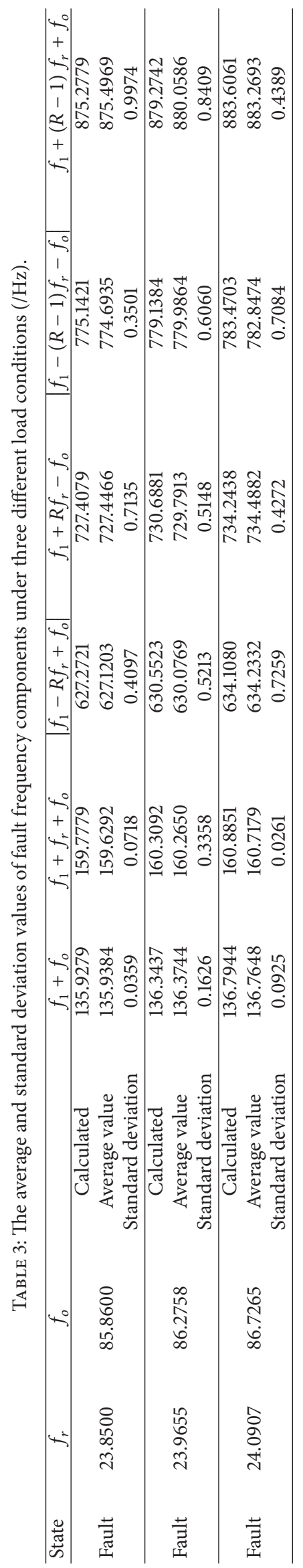


the frequency components at $\left|3 f_{1}-(R+1) f_{r}\right|$ and $\mid 3 f_{1}-$ $(R+2) f_{r} \mid$ are also observed with the faulty bearing, because of PSHs interaction with eccentricity harmonics (Figure 6(b)). This is true also of the frequency component at $f_{1}+(R-1) f_{r}$. The components at $\left|f_{1}-R f_{r}+f_{o}\right|$ and $f_{1}+R f_{r}-f_{o}$ do emerge in the situation of the outer raceway fault, but not in the health spectrum, as they are the result of an intermodulation between PSHs and the characteristic frequencies for bearing fault. Another two fault-related components at $\mid f_{1}-(R-1) f_{r}-$ $f_{o} \mid$ and $f_{1}+(R-1) f_{r}+f_{o}$ can also be observed in the case of the fault, owing to the effects of PSHs with eccentricity harmonics and bearing fault characteristic frequencies. The results attained by outer raceway fault prove, hence, earlier theoretical analysis.

In order to further prove the effectiveness of the proposed model for bearing fault detection, the current signals under several different load conditions have been processed using MATLAB. The offline experimental results are summarized in Tables 2 and 3. Table 2 highlights the presence of the fault frequency components and the magnitudes of these frequencies for healthy and faulty motors under these load conditions. Moreover, some average and standard deviation values of fault frequency components with a number of runs are also provided in Table 3 for the purpose of showing repeatability. In Table 3, there are six runs altogether for the same load conditions. From these experimental results we can clearly see that the proposed approach is reliable to be used for bearing fault detection. The estimated fundamental supply frequency is $f_{1}=50.0679 \mathrm{~Hz}$ in this paper.

\section{Conclusions}

This paper has studied the effects of the slot harmonics on the stator current signals in an induction motor with bearing fault. Based on the airgap flux density calculation by the product of the permeance and the MMF, a more comprehensive mathematical model has been obtained when considering not only inherent eccentricity but also the slot harmonics in an induction motor with bearing fault. Some experimental investigations in this paper have proved that some new characteristic fault frequencies can be found around the rotor slot harmonics in the stator current spectrum. These experimental results agree well with the theoretical inference and the new characteristic frequencies expression can be used as effective assessment indicator for bearing fault detection.

\section{Conflicts of Interest}

The authors declare that there are no conflicts of interest regarding the publication of this paper.

\section{Acknowledgments}

This research was supported by the Science and Technology Project of Liaoning Province, no. 2015020140, and the subproject of Shandong Independent Innovation and Achievements Transfer Project, no. 2014CGZH0601.

\section{References}

[1] P. Zhang, Y. Du, T. G. Habetler, and B. Lu, "A survey of condition monitoring and protection methods for medium-voltage induction motors," IEEE Transactions on Industry Applications, vol. 47, no. 1, pp. 34-46, 2011.

[2] M. Riera-Guasp, J. A. Antonino-Daviu, and G.-A. Capolino, "Advances in electrical machine, power electronic, and drive condition monitoring and fault detection: state of the art," IEEE Transactions on Industrial Electronics, vol. 62, no. 3, pp. 17461759, 2015.

[3] G. S. Maruthi and V. Hegde, "Application of MEMS accelerometer for detection and diagnosis of multiple faults in the roller element bearings of three phase induction motor," IEEE Sensors Journal, vol. 16, no. 1, pp. 145-152, 2016.

[4] X. Jin, M. Zhao, T. W. S. Chow, and M. Pecht, "Motor bearing fault diagnosis using trace ratio linear discriminant analysis," IEEE Transactions on Industrial Electronics, vol. 61, no. 5, pp. 2441-2451, 2014.

[5] P. E. William and M. W. Hoffman, "Identification of bearing faults using time domain zero-crossings," Mechanical Systems and Signal Processing, vol. 25, no. 8, pp. 3078-3088, 2011.

[6] F. Immovilli, A. Bellini, R. Rubini, and C. Tassoni, "Diagnosis of bearing faults in induction machines by vibration or current signals: a critical comparison," IEEE Transactions on Industry Applications, vol. 46, no. 4, pp. 1350-1359, 2010.

[7] D. Z. Li, W. Wang, and F. Ismail, "A spectrum synch technique for induction motor health condition monitoring," IEEE Transactions on Energy Conversion, vol. 30, no. 4, pp. 1348-1355, 2015.

[8] M. Irfan, N. Saad, R. Ibrahim, and V. S. Asirvadam, "Condition monitoring of induction motors via instantaneous power analysis," Journal of Intelligent Manufacturing, pp. 1-9, 2015.

[9] V. C. M. N. Leite, J. G. Borges Da Silva, G. F. C. Veloso et al., "Detection of localized bearing faults in induction machines by spectral kurtosis and envelope analysis of stator current," IEEE Transactions on Industrial Electronics, vol. 62, no. 3, pp. 18551865, 2015.

[10] E. H. El Bouchikhi, V. Choqueuse, and M. Benbouzid, "Induction machine faults detection using stator current parametric spectral estimation," Mechanical Systems and Signal Processing, vol. 52-53, no. 1, pp. 447-464, 2015.

[11] E. H. E. Bouchikhi, V. Choqueuse, and M. E. H. Benbouzid, "Current frequency spectral subtraction and its contribution to induction machines' bearings condition monitoring," IEEE Transactions on Energy Conversion, vol. 28, no. 1, pp. 135-144, 2013.

[12] E. C. C. Lau and H. W. Ngan, "Detection of motor bearing outer raceway defect by wavelet packet transformed motor current signature analysis," IEEE Transactions on Instrumentation and Measurement, vol. 59, no. 10, pp. 2683-2690, 2010.

[13] M. Blödt, P. Granjon, B. Raison, and G. Rostaing, "Models for bearing damage detection in induction motors using stator current monitoring," IEEE Transactions on Industrial Electronics, vol. 55, no. 4, pp. 1813-1822, 2008.

[14] R. R. Schoen, T. G. Habetler, and F. Kamran, "Motor bearing damage detection using stator current monitoring," IEEE Transactions on Industry Applications, vol. 31, no. 6, pp. 1274-1279, 1995.

[15] G. Z. Cheng, C. D. Qiu, X. B. Wu, and Z. G. Xue, "The amplitude feature of current eigenfrequency for motor bearing banded failure," Applied Mechanics and Materials, vol. 668-669, pp. 268272, 2014. 
[16] J. H. Ma, C. D. Qiu, J. J. Luo, and G. Z. Cheng, "The current eigenfrequencies for bearing fault of mixed eccentric motor based on amplitude modulation," Applied Mechanics and Materials, vol. 668-669, pp. 273-276, 2014.

[17] J. R. Stack, T. G. Habeter, and R. G. Harley, "Fault classification and fault signature production for rolling element bearings in electric machines," IEEE Transactions on Industry Applications, vol. 40, no. 3, pp. 735-739, 2004.

[18] I. Bediaga, X. Mendizabal, A. Arnaiz, and J. Munoa, "Ball bearing damage detection using traditional signal processing algorithms," IEEE Instrumentation and Measurement Magazine, vol. 16, no. 2, pp. 20-25, 2013.

[19] L. Frosini and E. Bassi, "Stator current and motor efficiency as indicators for different types of bearing faults in induction motors," IEEE Transactions on Industrial Electronics, vol. 57, no. 1, pp. 244-251, 2010.

[20] B. Li, M.-Y. Chow, Y. Tipsuwan, and J. C. Hung, "Neuralnetwork-based motor rolling bearing fault diagnosis," IEEE Transactions on Industrial Electronics, vol. 47, no. 5, pp. 10601069, 2000.

[21] J. Zarei and J. Poshtan, “An advanced Park's vectors approach for bearing fault detection," Tribology International, vol. 42, no. 2, pp. 213-219, 2009.

[22] F. Immovilli, M. Cocconcelli, A. Bellini, and R. Rubini, "Detection of generalized-roughness bearing fault by spectral-kurtosis energy of vibration or current signals," IEEE Transactions on Industrial Electronics, vol. 56, no. 11, pp. 4710-4717, 2009.

[23] H. Zoubek, S. Villwock, and M. Pacas, "Frequency response analysis for rolling-bearing damage diagnosis," IEEE Transactions on Industrial Electronics, vol. 55, no. 12, pp. 4270-4276, 2008.

[24] Y. Amirat, V. Choqueuse, and M. Benbouzid, "EEMD-based wind turbine bearing failure detection using the generator stator current homopolar component," Mechanical Systems and Signal Processing, vol. 41, no. 1-2, pp. 667-678, 2013.

[25] W. Zhou, T. G. Habetler, and R. G. Harley, "Bearing fault detection via stator current noise cancellation and statistical control," IEEE Transactions on Industrial Electronics, vol. 55, no. 12, pp. 4260-4269, 2008.

[26] P. Frauman, A. Burakov, and A. Arkkio, "Effects of the slot harmonics on the unbalanced magnetic pull in an induction motor with an eccentric rotor," IEEE Transactions on Magnetics, vol. 43, no. 8, pp. 3441-3444, 2007.

[27] H. Guldemir, "Detection of airgap eccentricity using line current spectrum of induction motors," Electric Power Systems Research, vol. 64, no. 2, pp. 109-117, 2003. 


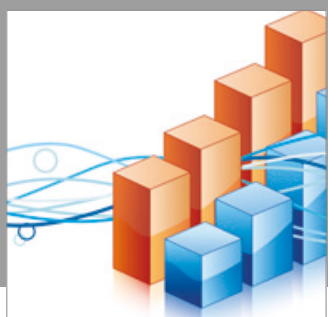

Advances in

Operations Research

vatersals

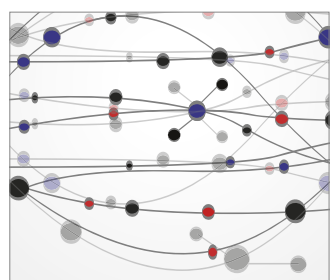

\section{The Scientific} World Journal
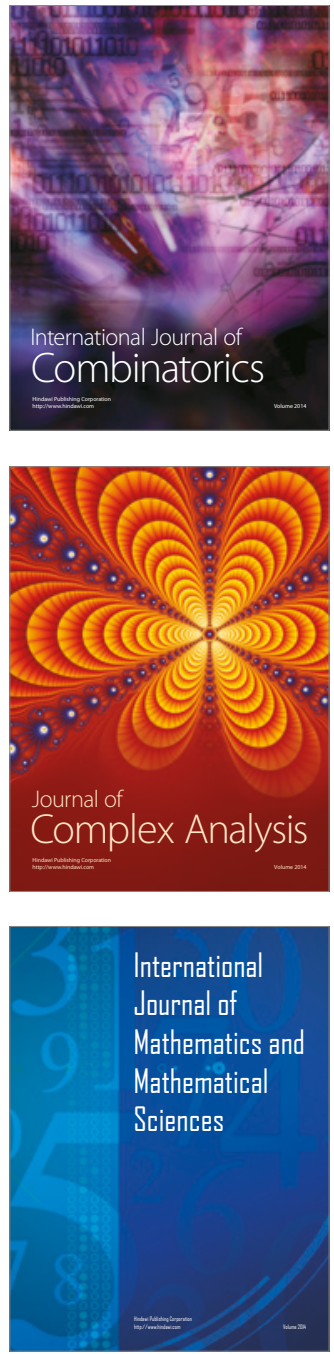
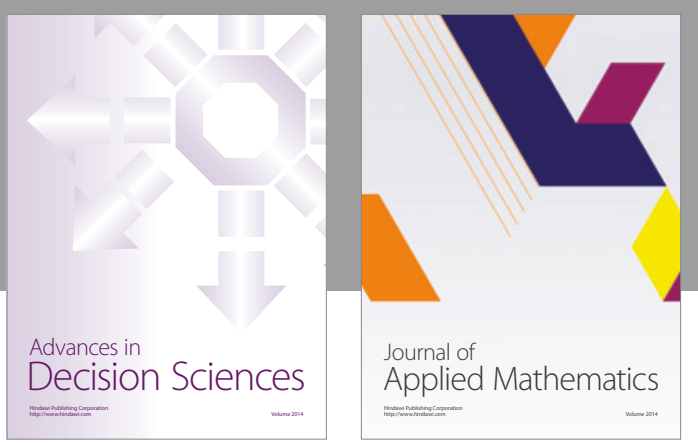

Algebra

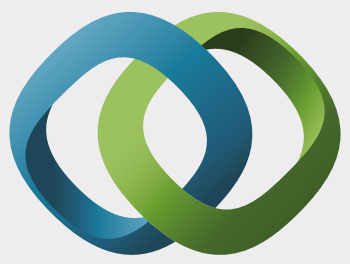

\section{Hindawi}

Submit your manuscripts at

https://www.hindawi.com
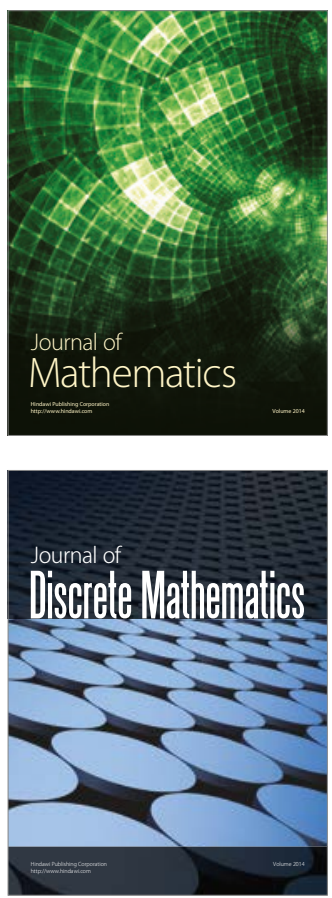

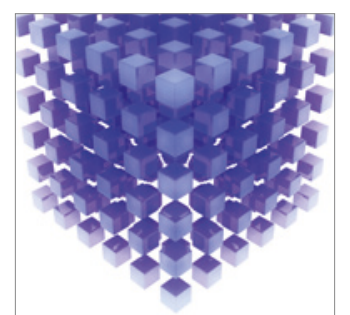

Mathematical Problems in Engineering
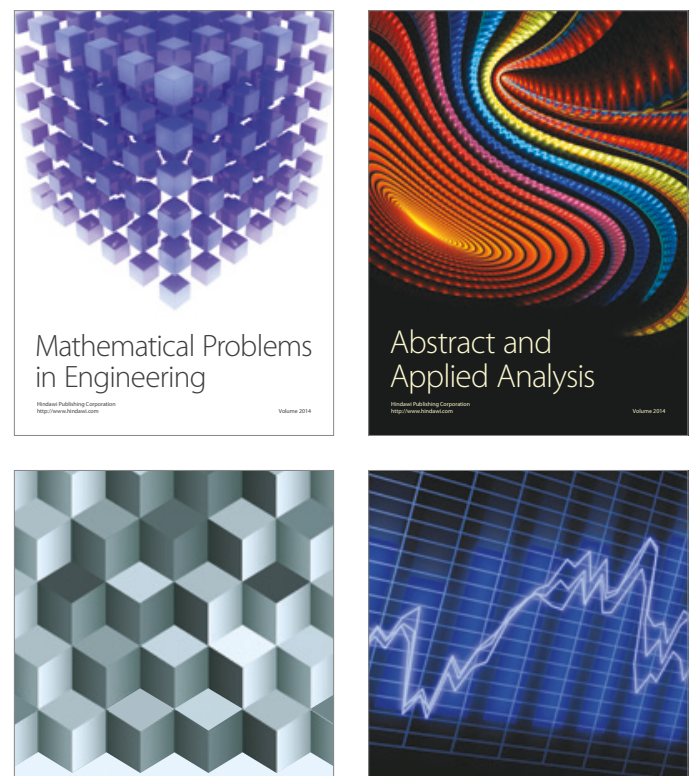

Journal of

Function Spaces

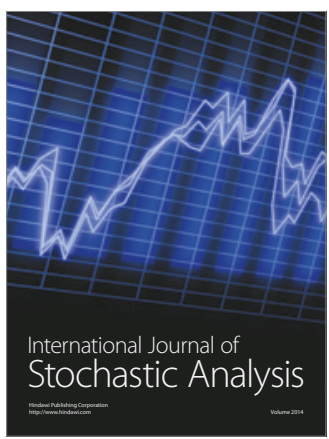

Probability and Statistics
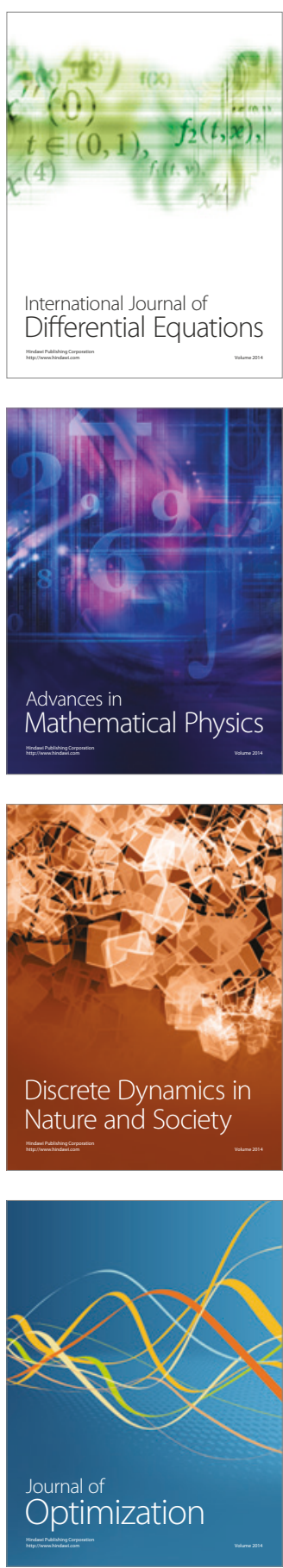